\title{
Documentos relativos a Juan Nicolás Böhl de Faber en el Ministerio Español de Asuntos Exteriores
}

GUILlERMO CARNERO

Universidad de Alicante

Se trata de veintiún documentos a los que no pude tener acceso en el momento de escribir mi libro de 1978 sobre los Böhl de Faber ${ }^{1}$, ya que no aparecen en el Catálogo del Archivo del Ministerio de Exteriores ${ }^{2}$. Conciernen a dos episodios concretos de la biografía de Juan Nicolás Böhl: su matrimonio y sus cargos consulares en España. Llamaré documentos de la serie $A$ a los tocantes al primero, y de las series $B$ y $C$ a los concernientes al segundo.

1 Los origenes del Romanticismo reaccionario español: el matrimonio Böhl de Faber. Valencia, Universidad, 1978.

2 M. Santiago Rodríguez, Los manuscritos del Archivo General y Biblioteca del Ministerio de Asuntos Exteriores. Madrid, Min. ${ }^{\circ}$ Exteriores, 1974. Por D. Francisco Aguilar Pinal tuve la primera noticia de la existencia en dicho Ministerio de documentos relacionados con Böhl, y, a decir verdad, la cosecha ha sido más abundante de lo que en principio pudo pensarse. Me ha sido posible acceder a ellos gracias a una intervención personal de D. Ernesto Lluch, Ministro de Sanidad, ante D. Fernando Morán, Ministro de Asuntos Exteriores. D. Luis Jessen, del gabinete de este último, se encargó de localizarlos y ponerlos a mi alcance. Conste aquí mi agradecimiento a todos ellos y al Sr. Morán por autorizarme no sólo a manejarlos, sino a reproducirlos. 


\section{Serie A}

En mi libro citado, pág. 73, se dice:

[Juan Nicolás Böhl] casó con Francisca de Larrea el 1-2-1796, como certifica el Poder para testar de 1819 en su pág. 5, y el Certificado de matrimonio publicado por Montoto.

Dicho Poder para testar consta en la bibliografía de la misma obra, págs. 302-303, sección Manuscritos, subsección Fondos Archivo Osborne, epígrafe Documentos biográficos, y viene así descrito:

Poder para testar, en papel sellado, 5 pliegos +1 sin sellar, concedido por $\mathrm{D}$. $^{\mathrm{a}}$ Francisca a su esposo, y en su defecto a D. Pedro Smitds y D. Juan José Beretarrechea, el 18-9-1819. Es copia del documento original, extendido por el notario Bernardo de La Calle en la misma fecha.

Dice D. ${ }^{a}$ Francisca en págs. 4-5 del Poder:

Contraxe mi Matrimonio legítimamente en esta mensionada Ciudad, con el memorado D. Juan Nicolás Bohl, al que intervino dispensación Pontificia mediante a que entonces era aquél de Religión Protestante, cuyo Consorcio se verificó en primero de febrero del año pasado de mil setecientos noventa y seis ...

El Versuch... de Elisa Campe (1858) es muy impreciso al respecto $^{3}$ y lo mismo Pitollet ${ }^{4}$. Las Notas Históricas-genealógicas y heráldicas... del Archivo Osborne tienen en cuenta la dispensa y dan la fecha correcta ${ }^{5}$, basándose en el certificado de matrimonio que publicó y perdió Montoto ${ }^{6}$.

La serie A consta de los siguientes documentos:

A.1. Instancia dirigida por Juan Nicolás Böhl, Francisca de Larrea y Francisca de Aherán (su madre) al Rey, con fecha 1 de septiembre de 1795 , solicitando gestión de dis-

3 Anónimo [Elisa Campe], Versuch einer Lebensskizze von Johann Nikolas Böhl von Faber..., s.1. [Leipzig], 1858, p. 20.

4 La querelle caldéronienne..., París, Alcan, 1909, p. 13.

5 Notas... p. 78. Ver Los orígenes..., p. 305.

6 S. Montoto, Fernán Caballero (Algo más que una biografía). Sevilla, 1969, pp. 10-11, n. III. 
pensa pontificia, por disparidad de cultos, para contraer matrimonio.

A.2. Adjunta a la anterior, fecha 31 de agosto, fe de muerte de Antonio Ruiz de Larrea, padre de la novia, que explica la ausencia de la firma del difunto en la instancia.

A.3. Oficio de Godoy a Azara, 20 de octubre de 1795, ordenando gestionar la dispensa.

Se observará en A.1. y A.3. que Böhl se hizo pasar por sueco y fue presentado por el Cónsul de Suecia ante las autoridades españolas. La superchería tiene sin duda su justificación en la conflictiva situación internacional entre Alemania, España y Francia en aquel año de 1795 que iba a presenciar los Tratados de Basilea.

\section{Series B y C}

En mis Origenes..., págs. 75-76, acepté las conclusiones de Dornhof ${ }^{7}$ en cuanto a los nombramientos consulares: 7 de enero de 1804 y 22 de enero de 1816. Tuve además en cuenta la solicitud por Böhl, conservada en el Archivo Osborne, del apellido nobiliario Von Faber, procedente del segundo matrimonio de su madre. La instancia es de 13 de febrero de 1806; y entre los documentos adjuntos a ella se encuentra copia de la patente extendida por el Senado de Lubeck, nombrándolo el 7 de enero de 1804 Cónsul Hanseático en Cádiz, nombramiento admitido en el Actạ Imperial de concesión del título solicitado, 8 de abril de 1806 . Según esta patente y los documentos que reproduzco más adelante, está equivocada Elisa Campe ${ }^{8}$ al situar los nombramientos en 1802 y 1807 , y lo mismo Pitollet ${ }^{9}$, que copia del Versuch... en este punto.

7 J. Dornhof, Johann Nikolaus Böhl von Faber..., Hamburgo, Seminar für romanische Sprachen und Kultur, 1925, p. VI.

8 Versuch..., p. 41.

9 Querelle..., p. 22. 
A la vista de los documentos que ahora publico, mis primitivas conclusiones y las aportaciones historiográficas en que me basé han de ser matizadas. En realidad, Juan Nicolás fue nombrado Cónsul Hanseático en 1804 y revalidado en 1816, en un primer momento por Hamburgo y posteriormente por Bremen y Lubeck. Los documentos de la serie B se refieren a lo primero, los de la serie $\mathrm{C}$ a lo segundo. Son los siguientes:

B.1. Oficio del Embajador Hanseático a Pedro Cevallos, 3 de abril de 1804; acompaña carta latina (y su copia) al Rey de España, y Patente de nombramiento, 7 de enero de 1804, de Cónsul de Hamburgo, Bremen y Lubeck, y solicita el exequatur real.

B.2. Adjunta a la anterior, carta latina (y copia) mencionada.

B.3. Borrador de oficio de Cevallos al Secretario de la Junta de Comercio, 5 de abril de 1804, ordenando informe sobre dicho nombramiento.

B.4. Borrador de oficio de Cevallos al Embajador Hanseático, 7 de junio de 1804, remitiendo el exequatur y devolviendo la Patente.

C.1. Nota sin fecha ni firma (ha de ser 1815 , y la letra parece de Böhl) solicitando confirmación del nombramiento consular y la pertinente gestión del Ministerio español de Estado. Con diligencia de Cevallos.

C.2. Borrador de oficio de Cevallos al Embajador español, 18 de diciembre de 1815 , ordenando dicha gestión.

C.3. Oficio del Embajador a Cevallos, 18 de enero de 1816; acompaña copia de otro del Síndico de Hamburgo, que confirma el nombramiento de Böhl por dicha ciudad y anuncia el envío de nueva Patente y las gestiones en curso y todavía no resueltas ante Bremen y Lubeck.

C.4. Nota interna, resumen del oficio anterior. Anotación de Cevallos.

C.5. Copia del oficio del Síndico de Hamburgo al Embajador, 18 de enero de 1816. 
C.6. Oficio del Embajador a Cevallos, 27 de enero de 1816, remitiendo la Patente hamburguesa.

C.7. Nota interna, resumen del oficio anterior.

C.8. Oficio de Cevallos a Manuel del Burgo, 20 de febrero de 1816 , ordenando informe sobre el nombramiento. Con diligencia de la Junta de Dependencias de Extranjeros.

C.9. Borrador del oficio anterior.

C.10. Oficio del Embajador a Cevallos, 9 de marzo de 1816, adjuntando Patentes de Bremen y Lubeck.

C.11. Nota interna, resumen del oficio anterior. Con diligencia de Cevallos.

C.12. Oficio de Cevallos a Manuel del Burgo, 29 de marzo de 1816 , ordenando informe sobre el anterior nombramiento. Con la misma diligencia que C.8.

C.13. Borrador del oficio anterior.

C.14. Oficio del Gobernador de Cádiz a Manuel del Burgo, 14 de abril de 1816, informando sobre los nombramientos.

No desarrollo en la transcripción abreviaturas de lectura evidente (Sn., Dn., dn., D. ${ }^{a}$, Exmo., Excmo., Sor., Sra., V.E., V.S., V.I., S.M., V.M., $\&^{a}$ ). Modernizo puntuación y acentuación.

Quiero dar las gracias a la profesora de Paleografía de la Facultad de Letras de Alicante, Dra. María Luisa Cabanes, por la ayuda que me ha prestado al descifrar algunas abreviaturas de escribano. 

Y CINCO.]

\section{Señor:}

Dn. Juan Nicolás Bohl, de Extracción Sueca, vezino y del Comercio de la plaza de Cádiz, y D. ${ }^{a}$ Francisca Xaviera Ruiz de Larrea, huérfana de padre que fue dn. Antonio Ruiz de Larrea, según consta por la fe de muerto que accompaña a esta venerente Súplica, y D. ${ }^{a}$ Francisca Aherán y Molone, Madre de la susodicha, a los Reales Pies de V.M. con la más profunda veneración hazen presente que los dos primeros han tratado contraher Matrimonio, el cual es de ygual interés a ambos. La diferencia en los dogmas de la Religión Cathólica que profesa la D. ${ }^{a}$ Francisca Xaviera, a la Lutherana que sigue el primero, requiere para celebrarlo legítimamente Dispensa Pontificia. Y a fin de dirigir la oportuna instancia con esperanza de su logro:

Suplican mui humildemente a V.M. se digne, concediendo su licencia y Protección, mandar a Su Embaxador en la Corte de Roma pida Dispensa correspondiente para que los que representan contraygan Matrimonio baxo aquellas Condiciones que el Zelo y la alta prudencia de Su Santidad estime necessarias y que en semejantes casos se acostumbran, y dignándose también V.M. mandar expedir la competente Real Orden en que se encargue su execución y cumplimiento a las Personas a quienes corresponda.

Así lo esperan de la piedad de V.M.

Cádiz y 1 de Septiembre 1795.

A Los Reales Pies de V.M.

Juan Nicolás Bohl [rubricado]

Francisca Xaviera Ruiz De Larrea.

Francisca Aherán y Molone [rubricado] 
ISELLO QUARTO, QUARENTA MARAVEDÍS, AÑO DE MIL SETECIENTOS NOVENTA Y CINCO.]

Yo el Doctor Don Antonio de Borica, Presbytero y Colector de la Parroquia de N. Sra. del Rosario de esta Ciudad: Certifico que en el Libro primero en donde se toma razón de las Personas que han fallecido en esta Parroquia, al folio secenta y cinco, se halla una partida que copiada a la letra es como se sigue $=$

En Cádiz, Sábado día siete de Septiembre de mil setecientos noventa y tres, se enterró por la mañana en el Convento de Sn. Augustín, con oficio de medias honras con Música, dn. Antonio Ruiz de Larrea, de edad de setenta y seis años, natural del Lugar de Mendiola, Provincia de Álaba en Viscalla, de estado casado / con/ D. ${ }^{a}$ Francisca Xaviera Aherán. Hizo disposición ante dn. Manuel Saenz, escribano público y del número de esta Ciudad, el día treinta de Agosto próximo anterior. Murió el día seis de dicho Mes y Año, haviendo recibido los Santos Sacramentos. Vivía en la Calle de Ahumada, y lo firmé ut supra. $=$ Dor. Dn. Antonio de Borica

Concuerda con su original, que queda en la Colecturía de la referida Parroquia, a que me refiero, y para que conste donde convenga, doy la presente en Cádiz a treinta y un días del Mes de Agosto de mil setecientos noventa y cinco años.------ Dor. D. Antonio de Borica [rubricado] 


\section{A.3.}

Excmo. Sor.:

El Cónsul General de Suecia ha acudido al Rey con el adjunto memorial en que D. Juan Nicolás Bahl, de nación sueco, vecino y del Comercio de la Plaza de Cádiz, y D. Francisca Xaviera Ruiz de Larrea, solicitan qùe el Papa les dispense los impedimentos de disparidad de culto con que se hallan, para llebar a efecto el matrimonio que tienen contratado; y lo remito a V. E. de Orden de S. M. para que impetre la citada dispensa y me la remita, si Su Santidad tubiese a bien concederla, con una nota de su coste, o incluyéndola en la Lista de las que se dirigen a $D$. Josef de Resa como se acostumbra, según parezca a V.E. Dios guarde a V. E. muchos años. Sn. Lorenzo 20 de Octubre de 1795.

\section{El Príncipe de la Paz [rubricado]}

Excmo. Sor. D. José Nicolás de Azara.

[Vuelto:

Sn. Lorenzo 20 de Octubre 1795

El Sor. Príncipe de la Paz

Dispensa matrimonial para dn. Juan Nicolás Bahl Sueco] 
A la Junta de comercio y véase la práctica observada con estas cartas del Senado de Lubec

el recivo

[letra de Cevallos] 1804

fecho 5 de Abril de

No se responde a las cartas Credenciales, coñque parece no debe tratarse éstas con mayor atención pues no tienen ni aun aquella calificación.

Remitida la patente al Señor Ministro en 7 de Junio de 1804. fecho a la Junta de Comercio en 5 de Abril de 1804

\section{N O T E}

Etant décédé à Cadix le Sieur Jean Auguste Riess, consul des Villes Anséatiques, le Sénat de Lubec en sa qualité de Directoire de la Confédération Anséatique a nommé pour son successeur le Sieur Jean Nicolas Bohl, Négociant Hambourgeois établi dans la dite Place, et a fait parvenir au soussigné Ministre Résident la lettre ci-jointe pour le Roi, accompagnée de la copie \& de la Patente ordinaire, avec ordre de présenter la première à Sa Majesté Catholique \& les secondes à Son Excellence Monsieur de Cevallos, Ministre \& Premier Secrétaire d'État, en le suppliant de vouloir bien proposer au Roi de daigner munir la dite Patente de son Royal Exequatur; le Sénat, espérant que nulle circonstance ne s'oppose à cette nomination, il se flatte que le choix que les Villes Anséatiques ont fait du Sieur Bohl trouvera l'approbation de Sa Majesté Catholique \& de son Ministère.

Le soussigné, se trouvant indisposé et ne pouvant avoir l'honneur de se mettre aux Pieds du Roi pour Lui présenter la lettre du Sénat, il prend 
la liberté de supplier Son Excellence Monsieur de Cevallos de vouloir bien s'en charger, et dans la persuasion qu'aucun empêchement ne sçauroit se présenter qui pourroit mettre de l'obstacle à l'expédition de l'Exequatur, le soussigné ose prier Son Excellence d'avoir la bonté de donner cours à cette affaire pour que le nouveau Consul soit au plustôt mis en état de remplir ses fonctions sur le pied ordinaire.

Le soussigné ayant au surplus l'honneur de réitérer à Son Excellence les assurances de sa haute considération \& de son dévouement respectueux.

Charles Andreoli [rubricado]

Madrid, le 3 Avril 1804

A S. E. Monsieur de Cevallos, Ministre et Premier Secrétaire d'État de Sa Majesté Catholique, \&c. \&c.

[Vuelto:

3 Avril 1804

El Ministro de las Ciudades Anseáticas

Patente de Cónsul en Cádiz al Sor. Nicolás Bohll, comerciante hamburgués.] 
AUGUSTISSIME ac POTENTISSIME REX CATHOLICE, DOMINE LONGE CLEMENTISSIME

Inter plurima insignis gratiae atque clementiae documenta, quibus SACRA REGIA CATHOLICA MAIESTAS VESTRA, EIUSQUE Praedecessores divae memoriae nobis, civitatibus nostris earumque comerciis per longissimi temporis tractum benigne prospicere voluerunt, exstat quoque concessa nobis facultas, in nostram nostrorumque mercatorum utilitatem, Consules Hanseaticos in emporiis Regni Hispanici constituendi.

Quum igitur post mortem Ioannis Augusti Riess, Consulis huc usque Hansae Teutonicae in portu Gaditano eius provinciam, viro nobili, Ioanni Nicolao Böhl, mercatori, demandavimus ad Solium REGIAE MAIESTATIS VESTRAE CATHOLICAE submissa deponimus vota, velit ILLA humillimo nostro desiderio gratiosissime annuere, itaque dictum nunc in portu Gaditano constitutum consulem nostrum probare et admittere, illique in nostris nostrorumque negotiis plenam fidem tribuere, nec non Summis Regni SUI Ministris, Praefectis Provinciarum Civitatumque Rectoribus in mandatis dare, ut illum hoc Consulis munere libere defungi sinant et patrocinio benevole suscipiant, quoties auxilia eorum implorare ipsi contingeret.

Quod quidem novum eximiae Regiae erga nos benevolentiae documentum summa semper animi devotione colemus, Deum Optimum Maximun, ut SACRAM REGIAM CATHOLICAM MAIESTATEM VESTRAM omnigena Regia felicitate cumulet et in seros usque annos salvam servet et incolumem, ferventissime obstestantes, nos denique et nostras civitates submissima mente prolixae REGIAE MAIESTATIS VESTRAE gratiae de meliori commendantes. 
SACRAE REGIAE CATHOLICAE MAIESTATIS VESTRAE

\author{
devotissimi \\ Consules et Senatores
}

Civitatum Lubecae, Bremae et Hamburgi.

\author{
Dabamus \\ sub sigillo \\ Civitatis Lubecae, \\ quo in rebus Hanseaticis \\ uti consuevimus \\ die VII Ianuarii \\ M D C C C I V.
}


B.3.

Al Secretario de la Real Junta de Comercio y moneda. Aranjuez 5 de Abril de 1804.

Adjunta remito a V.S. de Real orden una Patente de Cónsul que me ha enviado el Sor. Ministro Residente de las Ciudades Anseáticas, por la que,/y por fallecimiento de Dn. Juan Augusto Rhiess/, el Senado de Lubec, como Directorio de la Confederación Anseática, nombra por Cónsul/de dichas Ciudades/en Cádiz a Dn. Juan Nicolás Böhl, comerciante Hamburgués establecido en dicho Puerto afin de que, examinando esa Real Junta de comercio y moneda la expresada Patente, consulte a S. M. lo que tenga por conveniente. Dios guarde \&a. 
Al Sor. Ministro Residente de las Ciudades Anseáticas. Aranjuez 7 de Junio de 1804.

Muy Sor. mío: Remito a manos de V.S. el adjunto Regis Exequatur para que Dn. Juan Nicolás de Böhl pueda exercer las funciones de Cónsul de las Ciudades Anseáticas en Cádiz, en consequiencia de la solicitud que a este efecto me dirigió V.S. en 3 de Abril último, acompañando el nombramiento que de dicho sugeto ha hecho el Senado de Lubec como Directorio de la Confederación Anseática, cuyo documento devuelvo igualmente a V.S. para el uso correspondiente, hallándose ya evacuadas las formalidades de uso por este Ministerio.

Aprovecho \&a. 
C.1.

ע. Juan Nicolás Bohl, vecino de Cádiz desde 1785 y Cónsul de las Ciudades Hanseáticas reconocido por el Sor. D. Carlos IV en 6 de Junio de 1804, desea ser confirmado en este empleo por el Senado nuevamente formado de dichas Ciudades, a cuyo fin conducirían sin dilación alguna un par de renglones del Sor. Ministro de estado manifestando que la continuación de dicho Bohl en este Consulado le sería agradable.

Es pues el empeño procurar una esquela de dicho Sor. Ministro dirigida al Sor. de Arriaza o al mismo Bohl, con la expresión que la confirmación del dicho Bohl en su empleo sería de su satisfacción y del agrado de S.M., por conceptuarle addicto a la Nación Española y a su legítimo gobierno.

Si se añadiese que todas las distinciones que el Senado confiriese a dicho Bohl en la carrera diplomática serían bien vistas, podría ser para él de utilidad.

\section{Dígase a Yznardy que le recomiende [letra de Cevallos] fecho 18 de Diciembre según minuta}


C.2.

D. Juan Nicolás Bohl, vecino de Cádiz desde el año 1785 y Cónsul de las Ciudades Anseáticas en aquella Plaza, reconocido en 6 de Junio de 1804, desea ser confirmado en su destino por el actual gobierno de dichas Ciudades.

La conducta de este sujeto en la pasada época le hace acreedor a todas las consideraciones que pueda dispensarle ese gobierno, a cuyo efecto le recomendará V. S. eficazmente.

Dios guarde a V. S. muchos años. Madrid 18 de diciembre de 1815 .

Sor. D. José Yznardi. 


\title{
E X M O. S E Ñ O R :
}

MUY SEÑOR MÍO: Luego que llegó a mis manos el oficio de V.E. de 18 del mes próximo pasado, no perdí un momento en dar quantos pasos eran oportunos para conseguir que este Gobierno confirmase a Don Juan Nicolás Böhl en su anterior destino de Cónsul en Cádiz. Por la copia adjunta de un oficio que me ha escrito el Síndico, se servirá V.E. ver que el Senado accedió inmediatamente a los deseos que le manifesté. Verbalmente se me ha ofrecido que en breves días se me entregará la Patente a favor de Böhl, y luego que la reciba la remitiré a V.E. sin pérdida de tiempo.

Como las tres Ciudades Anseáticas no están acordes en el sistema de sus relaciones exteriores, me resta el dar los mismos pasos con los Senados de Lubeck y Bremen, lisongeándome que el resultado será igualmente favorable.

Deseoso que S.M. y Altezas disfruten la más completa salud, reitero a V.E. la expresión de mi respeto, y ruego a Dios guarde su vida muchos años. Hamburgo, 18 de Enero de 1816.

\author{
Excmo. Señor, \\ Besa La Mano de V. E. \\ su más atento y seguro servidor \\ Josef de Yznardy y Yzquierdo \\ [rubricado]
}

Exmo. Señor Don Pedro Cevallos, Primer Secretario de Estado y del Despacho \&a \&a \&a. 


\section{C.4.}

Hamburgo 18 de Enero de 1816.

El Ministro Residente de S. M.

Avisa que conforme a lo que S.E. se sirve prevenirle en su oficio del 18 del mes próximo pasado, ha dado los pasos oportunos para que este Gobierno confirmase a Dn. Juan Nicolás Böhl en su anterior destino de Cónsul en Cádiz. Remite la copia de un oficio que el Síndico le ha escrito participándole que el Senado había inmediatamente accedido a ello.

$$
\begin{gathered}
\text { véase por qué se le dio este encargo } \\
\text { [letra de Cevallos] } \\
\text { Exmo. Sr. } \\
\text { por la adjunta resolución }
\end{gathered}
$$

Recibido 11 febrero

[a la vuelta de C.3.] 
C.5.

Copia de un oficio del Síndico del 18 del corriente.

Monsieur le Ministre:

Je me suis empressé de rendre compte au Sénat de ce que vous m'avez fait l'honneur de me communiquer à l'égard du renouvellement de la Patente de Consul pour Mr. Jean Nicolas Böhl à Cadiz. Le Sénat a immédiatement accédé.

Il ne s'agit que de demander encore l'avis de la Chambre de Commerce comme c'est d'usage, mais je ne crains plus qu'il soit défavorable à la demande. Les conditions pour le Consul à Cadiz seront les mêmes que pour les autres Consuls de Hambourg; et quant au retranchement du traitement, il devra partager le sort des autres Consuls, qui en avoient assignés sur les anciens fonds de l'Amirauté, qui sont épuisés par les malheurs du temps.

Veuillez agréer, Monsieur le Ministre, les sentiments d'estime et de considération \&a. (signé). Oldenburg. À Monsieur le Ministre d' Espagne.

Es copia

Josef de Yznardy

y Yzquierdo [rubricado] 
C.6.

\title{
E X M O. S E Ñ O R :
}

MUY SEÑOR MíO: Consiguiente a lo que tuve el honor de informar a V.E. con fecha del 18 del corriente, adjunta tengo el gusto de remitir la Patente de Cónsul de Hamburgo en Cádiz y Sevilla a favor de Don Juan Nicolás Böhl.

Como según la constitución de este Gobierno el Senado no puede conceder estos empleos sin el consentimiento de la Cámara de comercio, ha sido bien difícil vencer la oposición que hasta ahora había ésta hecho al nombramiento de Böhl.

Dios conserve la vida de V.E. muchos años. Hamburgo, 27 de Enero de 1816.

\author{
Excmo. Señor, \\ Besa La Mano de V. E. \\ su más atento y seguro servidor \\ Josef de Yznardy y Yzquierdo
}

[rubricado]

Exmo. Señor Don Pedro Cevallos, Primer Secretario de Estado y del Despacho \&a \&a \&a. 


\section{C.7.}

Hamburgo 27 de Enero de 1816

El Ministro Residente de S. M.

Consiguiente a lo que informó en su carta del $18 \mathrm{del}$ corriente, tiene el gusto de remitir la Patente de Cónsul de Hamburgo en Cádiz y Sevilla a favor de Don Juan Nicolás Böhl.

dirigida al/Consejo de/Hacienda en 2 de febrero según minuta.

[a la vuelta de C.6.] 
Sala de Govierno de Junta de Dependencias de Extrangeros, a 28 de Febrero de 1816.

Vieron los Señores Li- De Real orden paso a manos de cenciados Cavallero, V.S. la patente de cónsul en Cádiz y Rascón, Bustos, Córdo- Sevilla dada por el Senado de Hamva, López Alcaraz, Par- burgo en favor de Dn. Juan Nicolás ga y Posadillo.

Publicada. Instrúyase Böhl, vecino de Cádiz, para que la Junta de dependencias de extrangecomo corresponde y luego pase al servicio fiscal.

[rubricado]

Con fecha $1 .^{\circ}$ de Marzo se pidieron informes al Capitán general de Cádiz, y con la de 4 se remitió la Patente al servicio de la Ynterpretación.

Sr. dn. Manuel del Burgo.

ros consulte a S.M. lo que se le ofrezca y parezca sobre su pase. Dios guarde a V.S. muchos años. Palacio 20 de Febrero de 1816.

Pedro Cevallos [rubricado] 
C.9.

De Real orden paso a manos de V.S. la patente de Cónsul en Cádiz y Sevilla dada por el Senado de Hamburgo en favor de d. Juan Nicolás Böhl vecino de Cádiz, para que la Junta de dependencias de extrangeros consulte a S.M. lo que se le ofrezca, y parezca sobre su pase . Dios guarde a V.S. muchos años. Palacio 20 de Febrero de 1816.

Sr. D. Manuel del Burgo. 


\title{
E X M O. S E Ñ OR :
}

MUY SEÑOR MÍO: Tengo el honor de remitir a V.E. las Patentes de los Senados de Lubeck y Bremen, confirmando a Don Juan Nicolás Böhl en el destino de Cónsul de las Ciudadés Anseáticas en Cádiz; y me es muy lisongero el haber podido desempeñar completamente el encargo que V.E. se sirvió hacerme en su carta del 18 de Diciembre último.

No ocurriendo hoy cosa alguna que merezca la atención de V.E., me ceñiré a expresar mis deseos de que S.M. y Altezas disfruten la más perfecta salud.

Reitero a V.E. la expresión de mi respeto y ruego a Dios guarde su vida muchos años. Hamburgo 9 de Marzo de 1816.

\author{
Excmo. Señor, \\ Besa La Mano de V. E. \\ su más atento y seguro servidor \\ Josef de Yznardy y Yzquierdo \\ [rubricado]
}

Exmo. Señor Don Pedro Cevallos, Primer Secretario de Estado y del Despacho \&a \&a \&a. 


\title{
C.11.
}

Hamburgo 9 de Marzo de 1816

El Ministro Residente de S. M.

Remite las Patentes de los Senados de Lubeck y Bremen, confirmando a Dn. Juan Nicolás Böhl en el destino de Cónsul de las Ciudades Anseáticas en Cádiz.

\author{
déseles curso para su examen \\ [letra de Cevallos] \\ fecho 29 de Marzo según minuta
}

[a la vuelta de C.10.] 
C.12.

Sala de Govierno de Junta de Dependencias de Extrangeros, a 2 de Abril de 1816.

Vieron los Señores Licenciados Cavallero, Bustos, Córdova, López, Company y Posadillo.

Publicada. Instrúyase como corresponde y luego pase al servicio fiscal.

[rubricado]

Con fecha 4 de Abril se remitieron las Patentes a la Secretaria de Ynterpretación, y con la misma se pidieron los informes al $\mathrm{Ca}$ pitán general y Governador de Cádiz.

De Real orden dirijo a V.I. las adjuntas patentes despachadas por las Ciudades anseáticas de Brema y Lubek, en favor de Dn. Juan Nicolás Böhl, confirmándole el destino de Cónsul que obtenía en el Puerto de Cádiz, para que en su vista informe el Consejo lo que se le ofrezca y parezca.

Lo que comunico a V. I. para su inteligencia y cumplimiento. Dios guarde a V.S. muchos años. Palacio 29 de Marzo de 1816.

Pedro Cevallos [rubricado]

Sor. dn. Manuel del Burgo. 
C.13.

A Dn. Manuel del Burgo.

Palacio 29 de Marzo de 1816.

De Real orden dirijo a V.S. las adjuntas patentes despachadas por las Ciudades Anseáticas de Brema y Lubek en favor de dn. Juan Nicolás Böhl, confirmándole el destino de Cónsul que obtenía en el Puerto de Cádiz, para que en su vista informe el Consejo lo que se le ofrezca y parezca.

Lo que comunico a V.S. para su inteligencia y cumplimiento. Dios \&a. 
C.14.

Gobierno de la Plaza de Cádiz

Para dar a V.S. el informe que se ha servido pedirme de orden de ese Tribunal en oficio de 4 del actual, acerca de D. Juan Nicolás Bohl, a quien el Gobierno de las Ciudades Anseáticas ha nombrado por Cónsul de su Nación en esta Plaza, pedí el oportuno al Real Tribunal del Consulado de ella, el qual evaquándolo me manifiesta lo que copio.

Exmo. Sor. = Por el oficio de V.E. fecha once del actual se ha instruido este Consulado del que inserta del Secretario del Supremo Consejo de Hacienda D. Manuel del Burgo, acerca de las circunstancias de D. Juan Nicolás Bohl, nombrado Cónsul de las Ciudades Anseáticas por aquel Gobierno. El referido Bohl es natural de Hamburgo, muy apreciable en este comercio por su decorosa conducta; vino a España habrá tiempo de treinta años, $y$ ha veinte que se casó con natural de estos Reynos, abrazando la Religión Católica Apostólica Romana. No ha hecho continuas ni dilatadas ausencias, ni tiene bienes raíces, pues desde luego se dedicó a la profesión del tráfico, y aunque subsiste matriculado bajo el pabellón de sus Nacionales, tiene pública abierta casa de giro, siendo en el día Director de Compañía de Seguros. Su Nación siempre ha tenido Cónsul y es conveniente que lo haya por el concurso de Buques y tráfico en esta Plaza de aquellos naturales. = Es quanto puede este Tribunal informar a V.E. en justo obsequio a la confianza de su pregunta.

$Y$ sin ofrecérseme cosa alguna que añadir a lo que queda indicado en el inserto informe del Tribunal del Consulado, lo manifiesto a V.S. para que ese Tribunal determine lo que tenga por conveniente.

Dios guarde a V.S. muchos años. Cádiz 14 de Abril de 1816.

El Marqués de Castelldosrius [rubricado] Sor. Dn. Manuel del Burgo. 